\title{
Public education: 12 years on
}

\author{
Deborah Hart and Jill Phillipson
}

One of the main objectives of the College's Charter is "to promote public education". The Public Education Committee, which was established in 1986, and is now a Special Committee of Council, has been actively promoting media coverage of College policy, materials for the general public, new research and information about good practice in psychiatry. A large part of the work of the Public Education Committee involves media activity, such as regular press releases, press conferences and responding on a daily basis to the growing number of media enquiries from all over the world.

In 1993 the Public Education Committee commissioned a qualitative and quantitative analysis of press cuttings relevant to the College and this analysis was recently repeated. The main objective was to establish the effectiveness of the College's media communications over a one-year period from June 1996 to May 1997.
Although the College regularly receives coverage on radio and television, it is difficult to analyse the contents of these media. This review therefore focuses on press coverage only.

The College clipping service provides the Public Education Committee with copies of articles which mention 'The Royal College of Psychiatrists', 'British Journal of Psychiatry' and the 'Psychiatric Bulletin'. The analysis sought to identify perceptions of, and attitudes towards, both the College and psychiatry in general. It also examined the positive and negative content of 'service'-related references and 'patient'-focused references.

Article details were all cross-referenced to reveal variations between region, date of publication or the type of media used. The press cuttings were assessed on the basis of their relevance to the College's specialities; public education materials; the use of stigmatising vocabulary; and the overall tone of the articles.

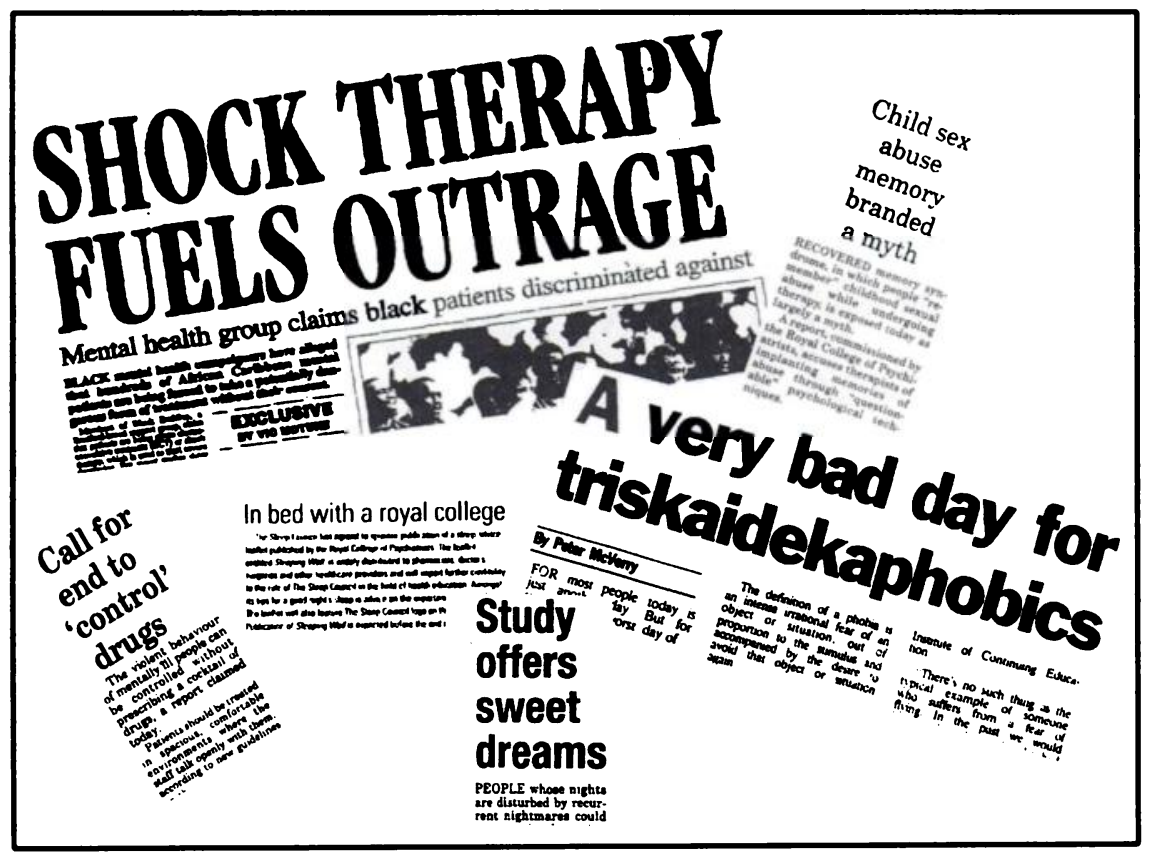

Figure 1. Newspaper headlines 
The 1997 data were then compared with the results of the 1993 survey to assess changing trends.

In 1993, 736 articles were analysed. By 1997 the total of articles analysed had doubled to more than 1500. Unfortunately, for cost reasons, we were able to analyse only 1292 of these, but the Public Education Committee believed that the analysis would be a representative sample.

Overall, the findings indicate that the College is receiving more positive than negative coverage. However, the opposite is true for psychiatry in general, which received more negative than positive coverage during the period from June 1996 to May 1997. Only 7\% of the references made to the College were negative compared with $54 \%$ relating to psychiatry in general. The main areas of negative coverage were concerned with Government policy in relation to community care such as attitudes towards patient services (45\%), deficiencies in psychiatric care/services (23\%) and 'treatments given, needed, available' (17\%) all of which can be grouped as service issues.

Contrary to expectation, as far as stigmatising vocabulary was concerned, in both 1993 and 1997 there was little use of derogatory terms in the articles analysed. The most commonly used words in this context were 'mad or madman' (6) and 'shrink' (3). 'Loony' and 'crazy' were each used once only.

The majority of press cuttings were from general newspapers (regional, broadsheet and tabloid). In 1997 they accounted for over $54 \%$ of the total press cuttings received.

England saw far more coverage than Scotland, Northern Ireland or Wales. However, it would be reasonable to expect this, due to the fact that there are more areas for regional newspapers to cover in England. The most prominent change which has occurred within these areas is Scotland, where coverage has doubled from 3 to $6 \%$. The regional newspapers tended to be more negative in their coverage while the paramedical and medical journals were the least critical.

There was a decrease in coverage of the College's educational materials, which was directly related to the reduction in the number launched during the period in question. However, coverage was consistent throughout the year, and overall the number of requests for leaflets and booklets has risen sharply, owing to general demand and interest in common mental health problems. Since the launch of the 'Depression' Help is at Hand leaflet in 1989.

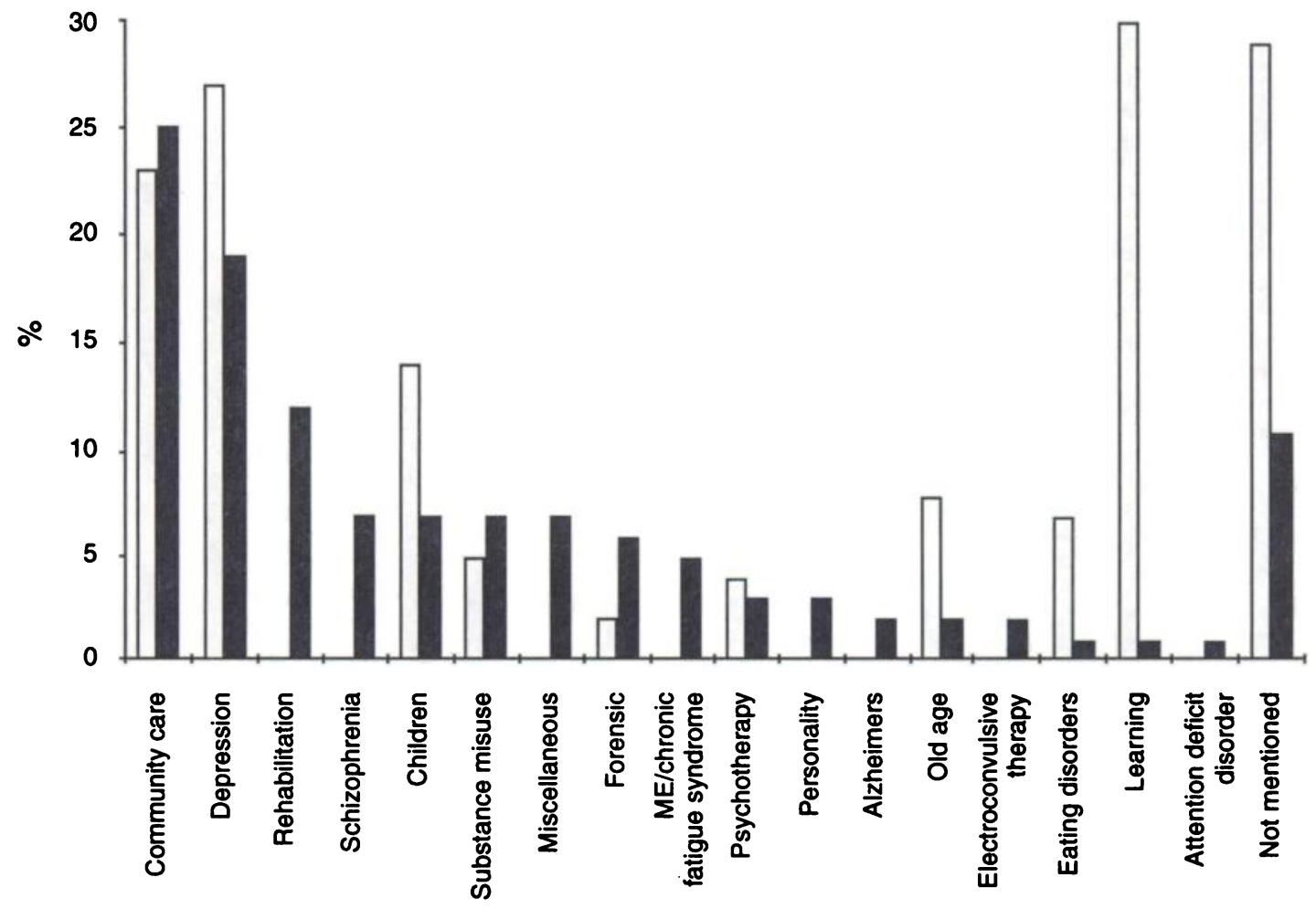

Figure 2. Mention of subjects relevant to College's area of specialism. $\square, 1993(n=739) ; \square,(n=1292)$. 


\section{THE COLLEGE}

more than five million of the College's series of leaflets have been requested and distributed, and the demand is increasing all the time.

Community care and depression accounted for the most coverage, followed by rehabilitation psychiatry and schizophrenia. The combined coverage of community care and depression accounted for $44 \%$ of total coverage. Issues surrounding community care were mainly found in newspapers $(26 \%)$, while issues relating to depression were featured both in medical jour nals (30\%) and magazines (23\%) (see Fig. 2). The most negative comments were concerned with the treatment and diagnosis issues such as electroconvulsive therapy and chronic fatigue syndrome. There was little coverage of subjects such as attention deficit disorder, learning disability and eating disorders. It must be born in mind, however, that all coverage is dependent on specific activities within the College relating to a particular speciality at a given time, as well as ad hoc news items and issues which become newsworthy for one reason or another.

Overall coverage of psychiatric issues was increasing and there were fewer peaks and troughs in 1997 than in 1993. Coverage is therefore more consistent. This can be explained by the fact that press releases on papers in the British Journal of Psychiatry and the Psychiatric Bulletin are sent out on a monthly basis and a consistent number of media enquiries during the course of the year.

The findings of the 1997 media coverage analysis have clearly provided data with greater depth than the 1993 research. The External Affairs Department relies on members of the College to field questions from the media and to offer themselves for interview, very often at short notice. We are most grateful to College members for helping us in this way. The number of members willing to work with the media has doubled over the past 10 years. It is an encouraging sign that psychiatrists are increas- ingly interested in communicating with the public through the media, thus helping to destigmatise mental disorders in general and psychiatry as a profession.

When reviewing the results of the 1997 media coverage analysis, it is salutary to remind ourselves that in the seven years preceding the establishment of the Public Education Committee, there were only three references to the College - sadly we do not know whether these were positive or negative!

\section{Summary}

- 'The Royal College of Psychiatrists' is receiving more positive press coverage than negative, which is the reverse for "psychiatry' in general.

- The use of stigmatising language was made in only a very small number of instances.

- Regional newspapers tended to reflect the most substantial negativity in coverage.

- Most areas of negativity were in relation either to 'community care' or changes/ potential changes to law or policy, primarily Government policy.

- 1997 saw a decrease in the coverage of the College's public education materials compared to 1993, although the coverage was consistent throughout the year.

- Overall coverage of psychiatric issues was on the increase.

- The most negative comments in terms of 'treatment' and 'diagnosis' were concerned with electroconvulsive therapy and chronic fatigue syndrome.

Deborah Hart, Head of External Affairs, and Jill Phillipson, College Adviser in Public Relations, Royal College of Psychiatrists, 17 Belgrave Square, London SWIX 8PG 